\title{
Numerical Study on Effects of the Embedded Monopile Foundation on Local Wave-Induced Porous Seabed Response
}

\author{
Chi Zhang, ${ }^{1,2}$ Qingyang Zhang, ${ }^{1}$ Zaitian Wu, ${ }^{3}$ Jisheng Zhang, \\ Titi Sui, ${ }^{1}$ and Yuncheng Wen ${ }^{4}$ \\ ${ }^{1}$ State Key Laboratory of Hydrology-Water Resources and Hydraulic Engineering, Hohai University, Nanjing, Jiangsu 210098, China \\ ${ }^{2}$ Key Laboratory of Engineering Sediment of Ministry of Transport, Tianjin Research Institute for Water Transport Engineering, \\ M.O.T., Tianjin, Tianjin 300456, China \\ ${ }^{3}$ Fujian Provincial Investigation Design and Research Institute of Port and Waterway, Fuzhou, Fujian 350002, China \\ ${ }^{4}$ Nanjing Hydraulic Research Institute, Nanjing, Jiangsu 210024, China
}

Correspondence should be addressed to Chi Zhang; zhangchi@hhu.edu.cn

Received 15 April 2015; Revised 21 July 2015; Accepted 26 July 2015

Academic Editor: Carla Faraci

Copyright (C) 2015 Chi Zhang et al. This is an open access article distributed under the Creative Commons Attribution License, which permits unrestricted use, distribution, and reproduction in any medium, provided the original work is properly cited.

Effects of the embedded monopile foundation on the local distributions of pore water pressure, soil stresses, and liquefaction are investigated in this study using a three-dimensional integrated numerical model. The model is based on a Reynolds-Averaged Navier-Stokes wave module and a fully dynamic poroelastic seabed module and has been validated with the analytical solution and experimental data. Results show that, compared to the situation without an embedded foundation, the embedded monopile foundation increases and decreases the maximum pore water pressure in the seabed around and below the foundation, respectively. The embedded monopile foundation also significantly modifies the distributions of the maximum effective soil stress around the foundation and causes a local concentration of soil stress below the two lower corners of foundation. A parametric study reveals that the effects of embedded monopile foundation on pore water pressure increase as the degrees of saturation and soil permeability decrease. The embedded monopile foundation tends to decrease the liquefaction depth around the structure, and this effect is relatively more obvious for greater degrees of saturation, greater soil permeabilities, and smaller wave heights.

\section{Introduction}

Monopile is a common structure used in ocean engineering, underneath which the porous seabed stability is a great concern for the structure safety $[1,2]$. The existence of a monopile will affect the wave-induced seabed response in two ways. First, a monopile will modify the propagation pattern of nearby waves (e.g., wave reflection and diffraction), which in turn results in the variations of pore water pressure and soil stresses inside the seabed. Second, the embedded monopile foundation will disturb the transmission of pore water pressure and soil stresses, leading to the local redistributions of these two quantities. Wave-seabed-monopile interaction may cause the liquefaction of surface soil layer and eventually the structure destruction. Better understanding and modeling of these mechanisms are important for the monopile design and maintenance in ocean engineering.
The numerical modeling of wave-seabed-monopile interaction has only recently become available [3]. This is mainly because the simulation of these processes requires an advanced three-dimensional (3D) integrated model including both complex wave transformation and seabed response around the monopile. Li et al. [4] developed a 3D numerical model for simulating wave-induced pore water pressure response around a monopile foundation. It is found that the amplitude of transient pore pressure decreases with the decrease of soil permeability. The development of pore pressure is also affected by wave nonlinearity and pile diameter. However, the second-order Stokes progressive wave theory was used in their study and both wave reflection and diffraction were not considered. Based on Reynolds-Averaged Navier-Stokes (RANS) equations and poroelastic seabed equations, a 3D integrated model was developed by Zhao et al. [5] to investigate wave-induced seabed response around breakwater heads, in 
which the seabed module was developed within COMSOL environment. This model was also applied by Chang and Jeng [6] to simulate the wave-seabed-structure interaction around the high-rising offshore wind turbine foundation used in the Donghai offshore wind farm, China. They found that the existence of the structure has a significant effect on the wave transformation and the distribution of wave-induced pore pressure. They also investigated effects of various wave and soil parameters on dynamic soil behavior and found that replacing the original seabed with coarse sand is efficient to prevent the seabed around pile tips from liquefaction. More recently, Sui et al. [7] used a 3D fully dynamic seabed model to investigate the seabed response beneath wave transformation around a monopile. They confirmed that wave reflection and diffraction have significant effects on pore water pressure and soil displacements around the monopile, and these effects increase with an increasing wave number. However, they did not investigate the seabed liquefaction around the monopile. The aforementioned studies have shown that the state-of-theart numerical models can reliably simulate the wave-seabedmonopile interaction and are very useful to investigate the underlying mechanisms. However, most of them focused on the seabed response to wave reflection and diffraction around a monopile, while the pure effects of the embedded monopile foundation on local seabed response are still not clear.

In this study, a 3D RANS wave model is integrated with a $3 \mathrm{D}$ fully dynamic poroelastic seabed model to investigate the effects of an embedded monopile foundation on the local distributions of pore water pressure, soil stresses, and liquefaction zone, under wave reflection and diffraction around a monopile. Both inertial terms of pore fluid and soil skeleton are included in the fully dynamic seabed model. In particular, we focus on the changes of maximum pore water pressure, maximum vertical effective normal soil stress, and maximum liquefaction depth due to the existence of an embedded monopile foundation. The significance of these effects with respect to various embedded depths and soil parameters is also discussed.

\section{Numerical Model}

The 3D numerical model used in this study was developed by integrating a wave module based on RANS equations and a seabed module based on Biot's poroelastic theory. The waveinduced dynamic water pressure at the seabed surface calculated by the wave module was employed as the external boundary condition of the seabed module.

2.1. Wave Module. The RANS equations for describing water wave motion can be expressed as

$$
\begin{aligned}
& \frac{\partial \rho_{f}}{\partial t}+\nabla \cdot\left(\rho_{f} \vec{u}_{f}\right)=0, \\
& \frac{\partial\left(\rho_{f} \vec{u}_{f}\right)}{\partial t}+\nabla \cdot\left(\rho_{f} \vec{u}_{f} \vec{u}_{f}\right) \\
& \quad=-\nabla p_{f}+\nabla \cdot \tau+F_{B}+F_{S}+F_{D},
\end{aligned}
$$

where $\rho_{f}$ is the water density, $\vec{u}_{f}$ is the velocity vector, $t$ is time, $\rho_{f}$ is water pressure, $\nabla \cdot \tau$ is the viscous force, and $F_{B}$, $F_{S}$, and $F_{D}$ are the body force, surface force, and drag force, respectively, in which only the body force $F_{B}$ is included in this study. The $k-\varepsilon$ two-equation turbulence model is used to provide turbulence closure for wave module [8]. Waves are generated within the computational domain by the internal wave-maker of Lin and Liu [9]. The free surface of water waves is captured by the volume of fluid (VOF) method.

2.2. Seabed Module. Based on Biot's poroelastic theory [1013], a fully dynamic mathematical description of the overall equilibrium of soil, the equilibrium of pore fluid flow, and the mass balance for porous seabed includes the accelerations of both soil and pore fluid. These can be expressed as

$$
\begin{array}{r}
\sigma_{i j, j}+\rho g_{i}-\rho_{f} \ddot{w}_{i}-\rho \ddot{u}_{i}=0, \\
-p_{, i}+\rho_{f} g_{i}-\frac{\rho_{f} g \dot{w}_{i}}{K_{i}}-\rho_{f} \ddot{u}_{i}-\frac{\rho_{f} \ddot{w}_{i}}{n^{\prime}}=0, \\
\dot{\varepsilon}_{i i}+\dot{w}_{i, i}+n^{\prime} \beta \dot{p}=0,
\end{array}
$$

where $\sigma_{i j}$ is the total stress, $p$ is the pore water pressure, $\rho$ is the total density of the porous medium, $g$ is the gravitational acceleration, $u_{i}$ is the displacement of soil matrix, $w_{i}$ is the average relative displacement of the fluid to the soil skeleton, $K_{i}$ is permeability of porous medium, $n^{\prime}$ is the porosity, $\varepsilon$ is the strain of the soil skeleton defined as $\varepsilon_{i j}=\left(u_{i, j}+u_{j, i}\right) / 2$, and $\beta$ is the compressibility of pore fluid defined as $\beta=$ $1 / K_{w}+\left(1-S_{r}\right) /\left(\rho_{f} g d\right)$, where $K_{w}$ is the bulk modulus of pore water, $d$ is the water depth, and $S_{r}$ is the degree of saturation. $K_{w}$ is typically taken as $1.95 \times 10^{9} \mathrm{~N} / \mathrm{m}^{2}$ following numerous studies $[13,14] . S_{r}$ is usually less than unity because of the gas storage in marine soil skeletons [15], and its value depends on the content of gas in marine sediments. It was reported that the degree of saturation significantly affects the wave-induced seabed response [13]. It is noted that the definition of $\beta$ is only suitable for nearly saturated seabed [16], that is, when $S_{r}$ is close to 1.0. This definition is assumed to be applicable to the test values of $S_{r}(=0.975-0.995)$ in this study in order to investigate the relationship between $S_{r}$ and the embedded monopile foundation effects.

The total stresses are given in terms of the effective stresses $\left(\sigma_{i j}^{\prime}\right)$ and pore pressure $(p)$ :

$$
\begin{aligned}
& \sigma_{i j}=\sigma_{i j}^{\prime}-\delta_{i j} p, \\
& \sigma_{i j}^{\prime}=\lambda u_{i, i} \delta_{i j}+2 G u_{i, i},
\end{aligned}
$$

where $\delta_{i j}$ is the Kronecker delta denotation, $\lambda=2 G \mu /(1-2 \mu)$, $G$ is shear modulus, and $\mu$ is Poisson's ratio.

In the present model, the linear elastic behavior of soil skeleton is considered. While the nonlinear or plastic soil behavior may be more obvious for large strains under longtime action of extreme waves, this study preliminarily focuses 
on the instantaneous seabed response on a relatively short time scale, for which the linear elastic concept is used as the first approximation due to its simplicity. This assumption was commonly made in the previous studies for wave-induced seabed response and gave satisfactory results $[4,6,14,17-20]$.

2.3. Boundary Conditions. In the wave module, the sponge layers are applied to eliminate wave reflection at the side/outlet boundaries. The boundary conditions for the momentum equations are based on the bottom stress estimated from the log-law. At the wave-seabed and wave-structure boundaries, nonslip conditions for velocities are imposed, and the turbulent kinetic energy $k$ and its dissipation rate $\varepsilon$ are specified from the "law of the wall" boundary condition following the traditional approach of Rodi [8]. At the air-water interface, zero surface tension is assumed, and both $k$ and $\varepsilon$ are implemented with the zero-gradient boundary conditions.

In the seabed module, the bottom and the lateral boundaries of the seabed are considered impermeable and rigid, where the soil and pore fluid displacements and the normal gradient of pore water pressure are zero. At the seabed surface, the pore water pressure is equal to the wave-induced dynamic water pressure, and the vertical effective normal stress and shear stresses of soil are negligible as they are very small compared to the wave-induced dynamic pressure (less than $2 \%$ in this study). Since the excess pore water pressure is the dominant factor for liquefaction, the neglect of soil stresses at the seabed surface is considered to have little influence on liquefaction calculation. This treatment was adopted in most numerical studies [18-21].

For dealing with the effects of embedded monopile foundation on seabed response, appropriate seabed-structure boundary conditions are necessary. Unlike other model studies that solve the responses of seabed and structure as a whole system, the present model includes an internal seabed-structure boundary condition to ensure the normal gradient of pore water pressure equal to zero $(\partial p / \partial n=0)$ at the impermeable and rigid structure surface. In addition, no relative displacement of soil with respect to structure $\left(u_{\text {soil }}=\right.$ $\left.u_{\text {structure }}\right)$ and the total stress equilibrium $\left(\sigma_{\text {structure }}=\sigma_{\text {soil }}^{\prime}-p\right.$, $\left.\tau_{\text {structure }}=\tau_{\text {soil }}\right)$ are also imposed at the seabed-structure boundaries.

2.4. Numerical Scheme. In the wave module, the RANS governing equations are solved using a two-step projection method with a finite volume discretization [22]. A set of unstructured triangular grids are adopted to discretize the computational domain. In the vicinity of monopile foundation, the grid size is $0.05 \mathrm{~m}$ in the horizontal plane and $0.5 \mathrm{~m}$ in the vertical direction, respectively. The fluid variables, such as the pressure and the velocities, are defined at the cell centroids. To convert cell centroid data to the face centroid to evaluate the gradient of the quantity at the cell centroid, the least square linear reconstruction method developed by Barth [23] is applied. The forward time difference method is used for the discretization of the time derivative. To obtain computational stability, the time interval is automatically adjusted at each time step to satisfy the Courant-Friedrichs-Lewy condition and the diffusive limit condition [24], with a range between $0.005 \mathrm{~s}$ and $0.05 \mathrm{~s}$.

In the seabed module, the second-order Crank-Nicolson type implicit Finite-Difference-Method is used to discretize governing equations, in combination with a staggered nonuniform rectangular grid. The Alternating-Direction-Implicit method and the Leap-Frog method are used to solve the multivariables in the differential equations with multidimensions. The underrelaxation technique is employed in iterative procedure to obtain convergent solutions. The grid size is $0.25 \mathrm{~m}$ in the horizontal plane and is $0.07 \mathrm{~m}$ in the vertical direction near the monopile, respectively. The time interval of seabed module is the same to wave module. The computational convergence of the numerical model is achieved when the maximum relative difference of solutions is less than 0.001 between any two successive iterations. This convergence is typically obtained within 100 iterations at each time step.

Considering that the movement of monopile is very small and has little effects on wave propagation, the integration of wave and seabed module is established as a so-called oneway coupling. The meshes of two modules are not required to match with each other at the wave-seabed interface. At each time step, the 3D field of dynamic wave pressure calculated by wave module is interpolated to the grid points of seabed module at the interface, driving the seabed module as the pressure boundary condition. This 3D interpolation of wave pressure is processed by an open source program of KT3D [25]. KT3D provides a fairly advanced 3D kriging program for points or blocks by simple kriging, ordinary kriging, or kriging with a polynomial trend model with up to nine monomial terms. More information of this program is available in reference [25].

\section{Model Validation}

In this section, we provide model validation with both the analytical solution and the experimental data. Figure 1 shows comparisons of the maximum pore water pressure and effective stresses between numerical results and the analytical solution of Hsu and Jeng [26] for seabed response under obliquely incident linear waves with an angle of 45 degrees. Figure 2 presents comparisons of the maximum pore water pressure between numerical results and the experimental data of Maeno and Hasegawa [27] for normally incident linear wave-induced seabed response. As shown, the model agrees well with both the analytical solution and the experimental data, demonstrating the numerical accuracy of the present model. More validation cases for the seabed model with different datasets are available in Sui et al. [7].

\section{Results and Discussion}

The model is applied to investigate the effects of embedded monopile foundation on local seabed response under wave transformation around a monopile. The incident waves have various heights $(2.0 \mathrm{~m}, 3.0 \mathrm{~m}, 3.5 \mathrm{~m}$, and $4.0 \mathrm{~m})$, periods $(4.0 \mathrm{~s}$ and $10.0 \mathrm{~s})$, and a water depth of $10 \mathrm{~m}$. The seabed thickness is $20 \mathrm{~m}$. The monopile has a pile radius of $3.0 \mathrm{~m}$, a length of 


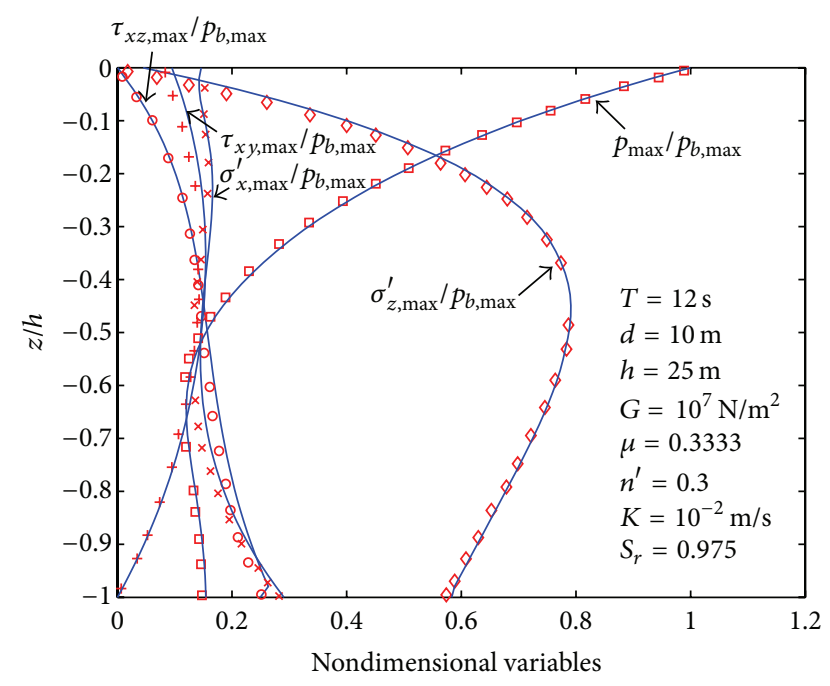

FIGURE 1: Comparisons of the maximum pore water pressure and effective stresses between numerical results (solid lines) and the analytical solution (symbols) of Hsu and Jeng [26].

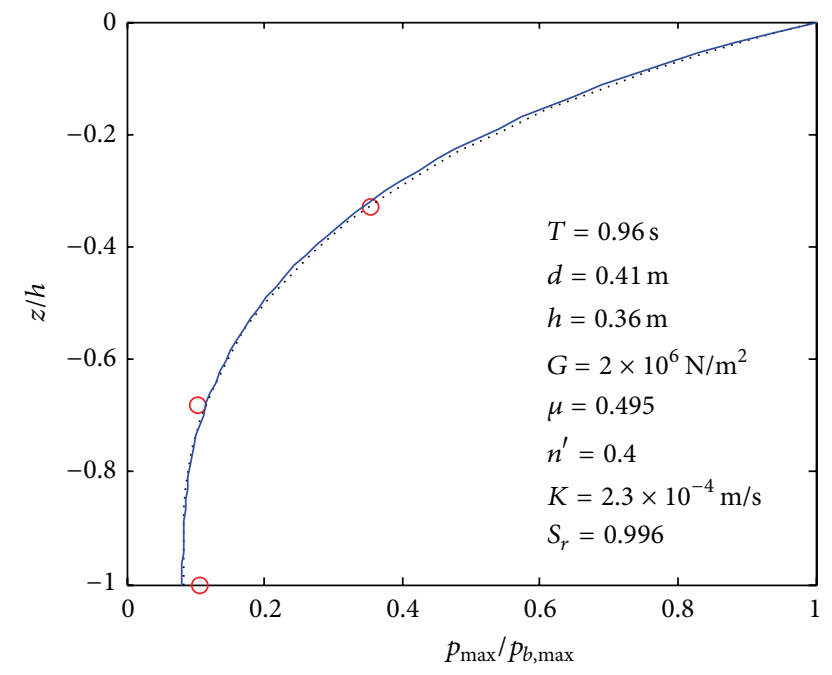

FIGURE 2: Comparisons of the maximum pore water pressure between numerical results (solid lines), the analytical solution (dotted line) of Hsu and Jeng [26], and the experimental data (circles) of Maeno and Hasegawa [27].

$17.5 \mathrm{~m}$ above the seabed, and various embedded depths $(0 \mathrm{~m}$, $5 \mathrm{~m}, 7.5 \mathrm{~m}$, and $10 \mathrm{~m}$ ) inside the seabed. The detailed input parameters are listed in Table 1. The distributions of wave characteristics, pore water pressure, soil displacements, and soil stresses are simulated. It is noted that, in the present computation, all of the inertial terms in (2) and (3) are considered. We have also tested various versions of the model, including the partly dynamic model (neglecting the acceleration of the pore fluid) and the quasi-static model (neglecting both acceleration terms of the pore fluid and the soil skeleton).

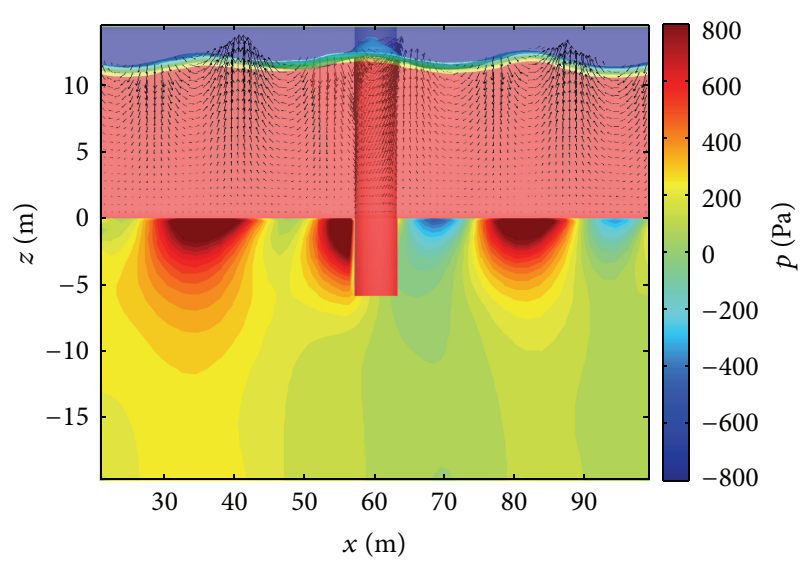

FIGURE 3: A snapshot of the simulated wave field and pore water pressure distribution at middle $x-z$ section.

TABLE 1: Input parameters.

\begin{tabular}{|c|c|c|}
\hline \multicolumn{2}{|c|}{ Wave parameters } & Unit \\
\hline Wave height, $H$ & $2.0,3.0,3.5,4.0$ & $\mathrm{~m}$ \\
\hline Wave period, $T$ & $4.0,10.0$ & s \\
\hline Water depth, $d$ & 10.0 & $\mathrm{~m}$ \\
\hline \multicolumn{3}{|c|}{ Seabed parameters } \\
\hline Thickness of seabed, $h$ & 20.0 & $\mathrm{~m}$ \\
\hline Density of pore fluid, $\rho_{f}$ & $1.0 \times 10^{3}$ & $\mathrm{~kg} / \mathrm{m}^{3}$ \\
\hline Bulk modulus of water, $K_{w}$ & $1.95 \times 10^{9}$ & $\mathrm{~N} / \mathrm{m}^{2}$ \\
\hline Density of soil, $\rho_{s}$ & $2.65 \times 10^{3}$ & $\mathrm{~kg} / \mathrm{m}^{3}$ \\
\hline Soil porosity, $n^{\prime}$ & 0.3 & - \\
\hline Degree of saturation, $S_{r}$ & $0.975,0.980,0.985,0.995$ & - \\
\hline Soil permeability, $K$ & $\begin{array}{l}5 \times 10^{-5}, 5 \times 10^{-4} \\
5 \times 10^{-3}, 5 \times 10^{-2}\end{array}$ & $\mathrm{~m} / \mathrm{s}$ \\
\hline Shear modulus, $G$ & $5 \times 10^{6}$ & $\mathrm{~N} / \mathrm{m}^{2}$ \\
\hline Poisson's radio, $\mu$ & 0.3333 & - \\
\hline \multicolumn{3}{|c|}{ Monopile parameters } \\
\hline Pile radius, $r$ & 3.0 & $\mathrm{~m}$ \\
\hline Pile length, $l$ & 17.5 & $\mathrm{~m}$ \\
\hline Embedded depth, $d_{e}$ & $0,5.0,7.5,10.0$ & $\mathrm{~m}$ \\
\hline Density of structure, $\rho_{s}$ & $2.65 \times 10^{3}$ & $\mathrm{~kg} / \mathrm{m}^{3}$ \\
\hline Shear modulus, $G$ & $5 \times 10^{9}$ & $\mathrm{~N} / \mathrm{m}^{2}$ \\
\hline Poisson's radio, $\mu$ & 0.3333 & - \\
\hline
\end{tabular}

The resulting differences are generally less than $0.005 \%$ for the partly dynamic model and less than $3 \%$ for the quasi-static model, respectively. This indicates that the inertial terms are not significant in this study.

Figures 3 and 4 are snapshots of the simulated results. It is found that the pore water pressure distribution is significantly controlled by the surface wave transformation pattern around the monopile foundation above the seabed, for example, the convergence and divergence of pore water pressure in front 


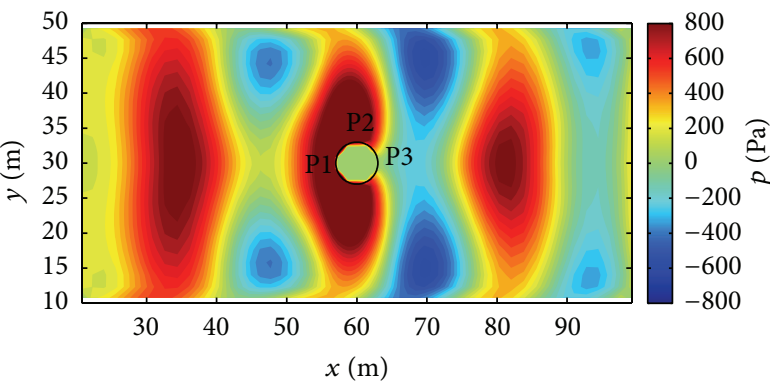

(a)

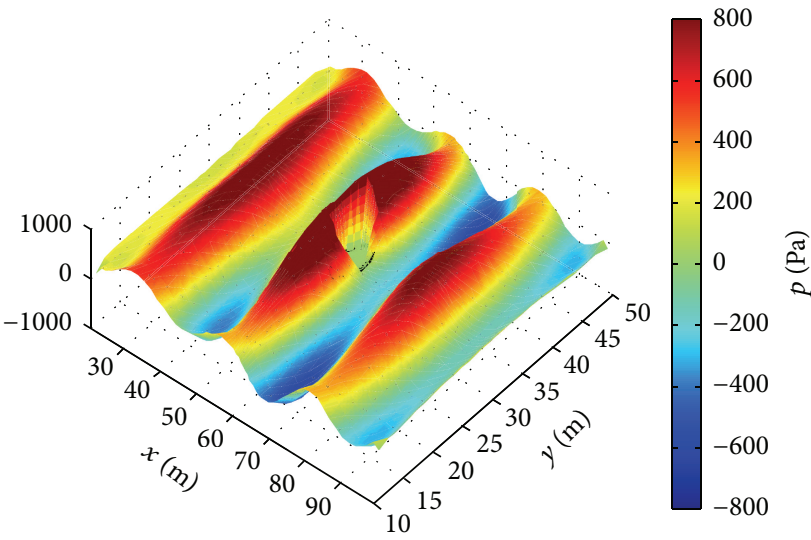

(b)

FIGURE 4: Snapshots of the simulated pore water pressure distribution at $z=-1.45 \mathrm{~m}$ (a) at $x-y$ section and (b) from a 3D perspective.

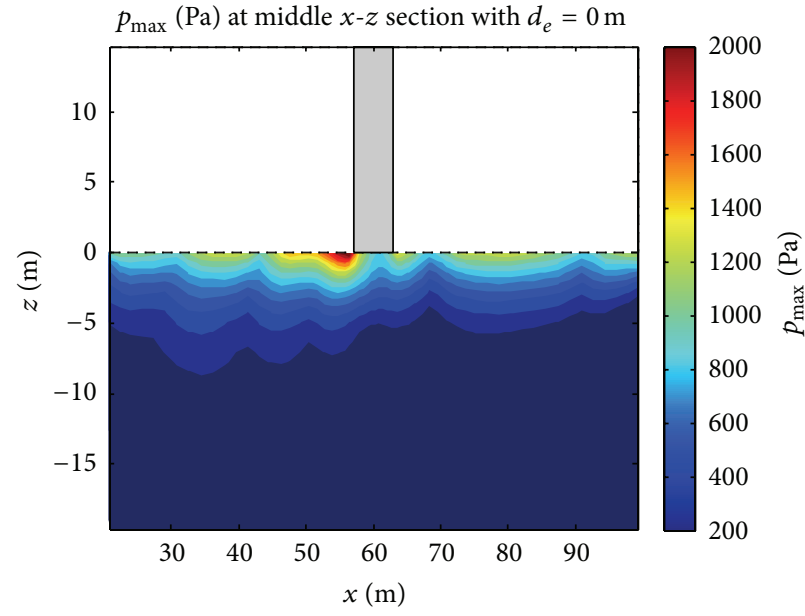

(a)

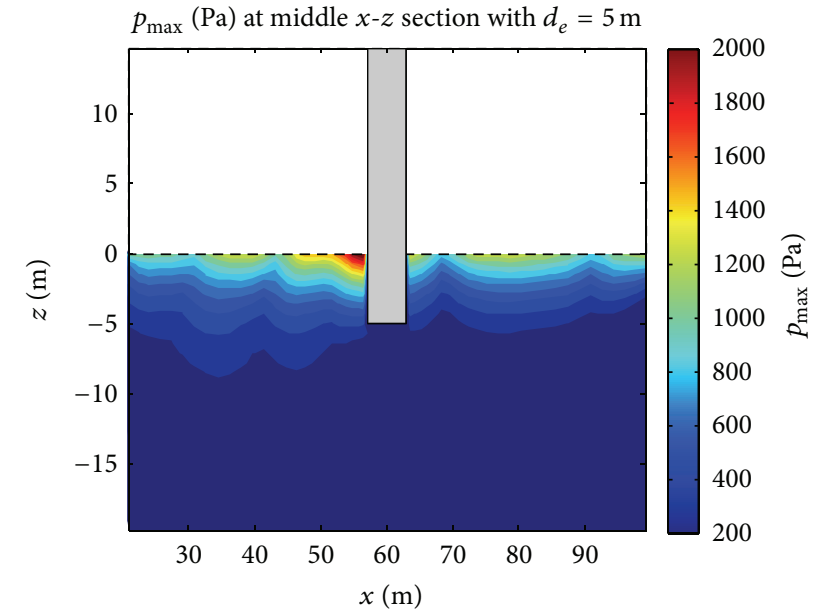

(b)

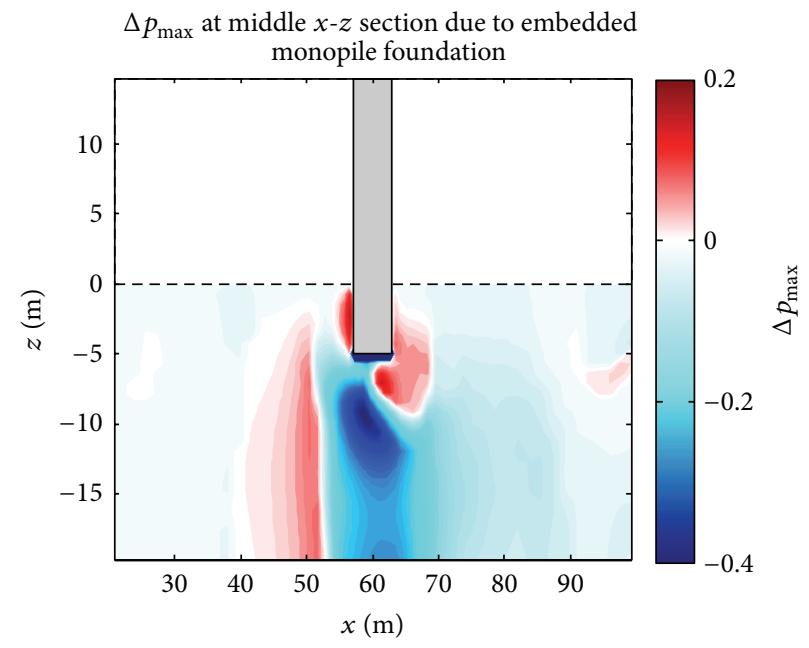

(c)

FIGURE 5: Distributions of the maximum pore water pressure at middle $x-z$ section with the embedded depth $d_{e}=0 \mathrm{~m}(\mathrm{a}), d_{e}=5 \mathrm{~m}(\mathrm{~b})$, and its relative change (c) due to the embedded monopile foundation $\left(H=2 \mathrm{~m}, T=4 \mathrm{~s}, S_{r}=0.985\right.$, and $\left.K=5 \times 10^{-3} \mathrm{~m} / \mathrm{s}\right)$. 


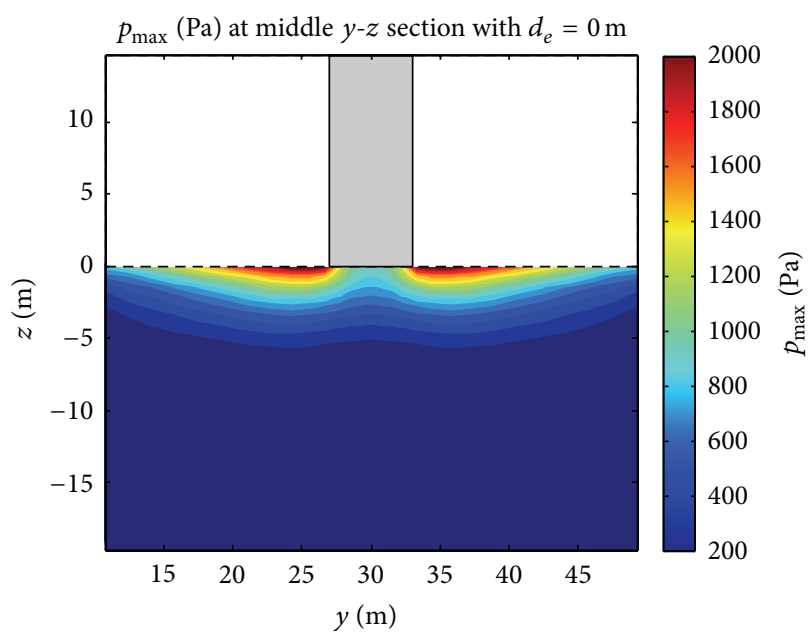

(a)

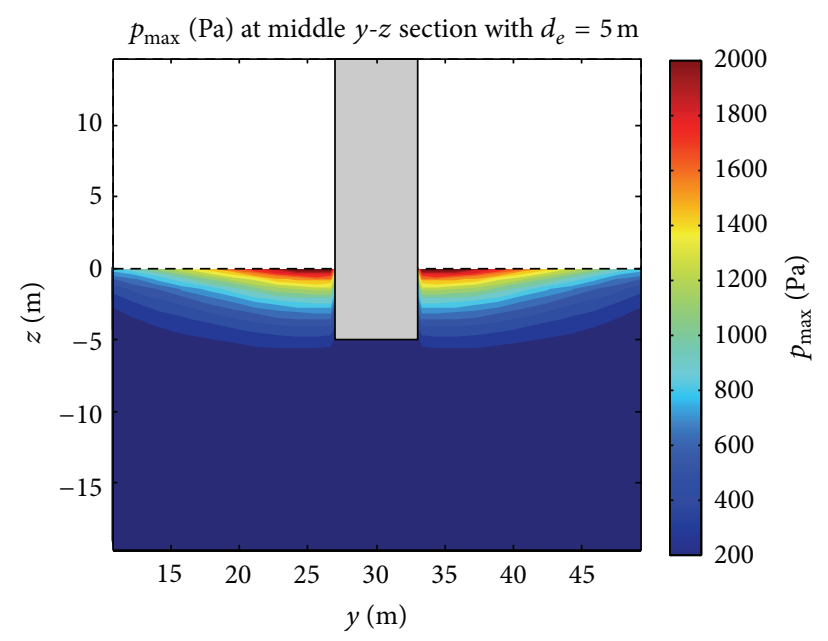

(b)

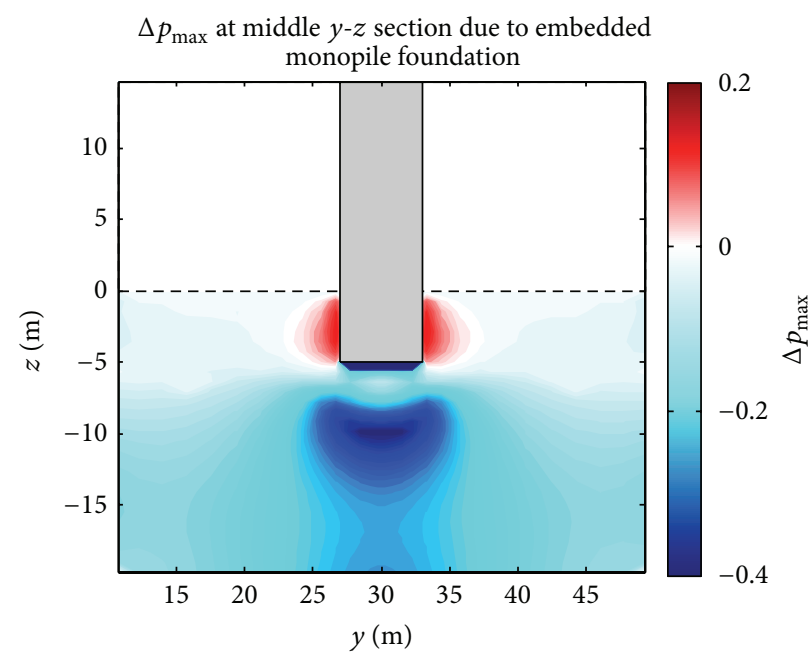

(c)

FIGURE 6: Distributions of the maximum pore water pressure at middle $y-z$ section with the embedded depth $d_{e}=0 \mathrm{~m}$ (a), $d_{e}=5 \mathrm{~m}$ (b), and its relative change (c) due to the embedded monopile foundation $\left(H=2 \mathrm{~m}, T=4 \mathrm{~s}, S_{r}=0.985\right.$, and $\left.K=5 \times 10^{-3} \mathrm{~m} / \mathrm{s}\right)$.

and lee sides of monopile due to surface wave reflection and diffraction, respectively. In the following analysis, we will focus on how the embedded monopile foundation inside the seabed changes the local pore water pressure and soil stress.

4.1. Change of Pore Water Pressure due to the Embedded Monopile Foundation. Figure 5 shows the distributions of the maximum pore water pressure $\left(p_{\max }\right)$ at middle $x-z$ section with the embedded depth, $d_{e}=0 \mathrm{~m}$ and $d_{e}=5 \mathrm{~m}$, and its relative change $\left(\Delta p_{\max }\right)$, where $\Delta p_{\max }=\left(p_{\max , d_{e}=5}-p_{\max , d_{e}=0}\right) /$ $p_{\max , d_{e}=0}$. It is found in Figures 5(a) and 5(b) that $p_{\max }$ at front side is larger than at lee side of monopile. This is due to the fact that the reflected wave height at front side is larger than the diffracted wave height at lee side. $p_{\max }$ peaks just in vicinity of the monopile foundation and decreases with increasing distance to monopile where the wave reflection effect is less significant. As shown in Figure 5(c), the main effects of embedded monopile foundation on pore water pressure are to increase $p_{\max }$ near both front and lee sides of foundation and decrease $p_{\max }$ in the majority of seabed below the foundation. Figure 6 shows the results at middle $y-z$ section. Symmetric $p_{\max }$ distribution is seen at both lateral sides of monopile foundation. Similar to Figure 5, $p_{\max }$ increases at both lateral sides and decreases below the foundation. This is because the existence of embedded structure partly blocks the pore water motion in the horizontal directions, promotes the vertical transmission of pore water pressure, and thus increases the magnitude of pore water pressure nearby.

4.2. Change of Effective Soil Stresses due to the Embedded Monopile Foundation. Figure 7 shows the distributions of the maximum vertical effective normal soil stress $\left(\sigma_{z, \max }^{\prime}\right)$ at middle $x-z$ section with the embedded depth, $d_{e}=0 \mathrm{~m}$ and $d_{e}=5 \mathrm{~m}$, and its relative change $\left(\Delta \sigma_{z, \max }^{\prime}\right)$, where $\Delta \sigma_{z, \max }^{\prime}=$ $\left(\sigma_{z, \max , d_{\mathrm{e}}=5}^{\prime}-\sigma_{z, \max , d_{\mathrm{e}}=0}^{\prime}\right) / \sigma_{z, \max , d_{\mathrm{e}}=0}^{\prime}$. It is found in Figures $7(\mathrm{a})$ and $7(\mathrm{~b})$ that $\sigma_{z, \max }^{\prime}$ quickly increases with increasing 


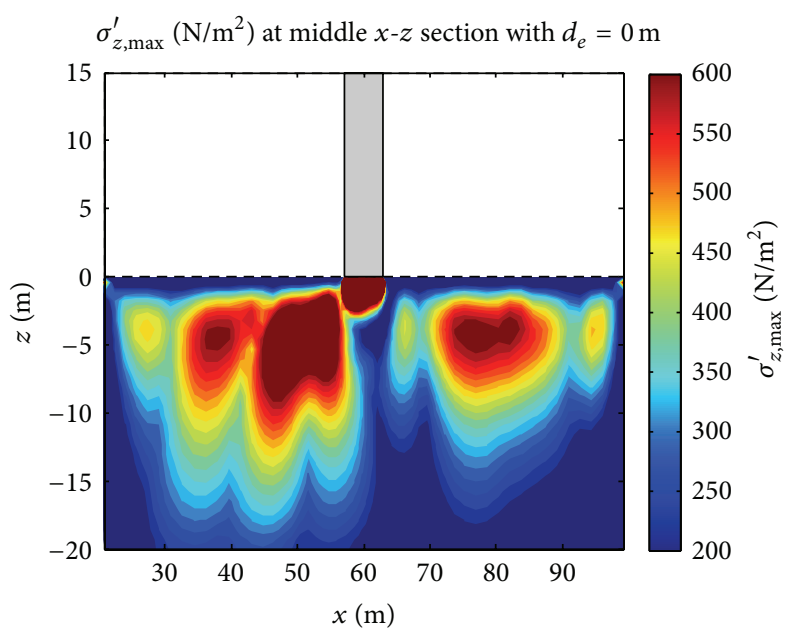

(a)

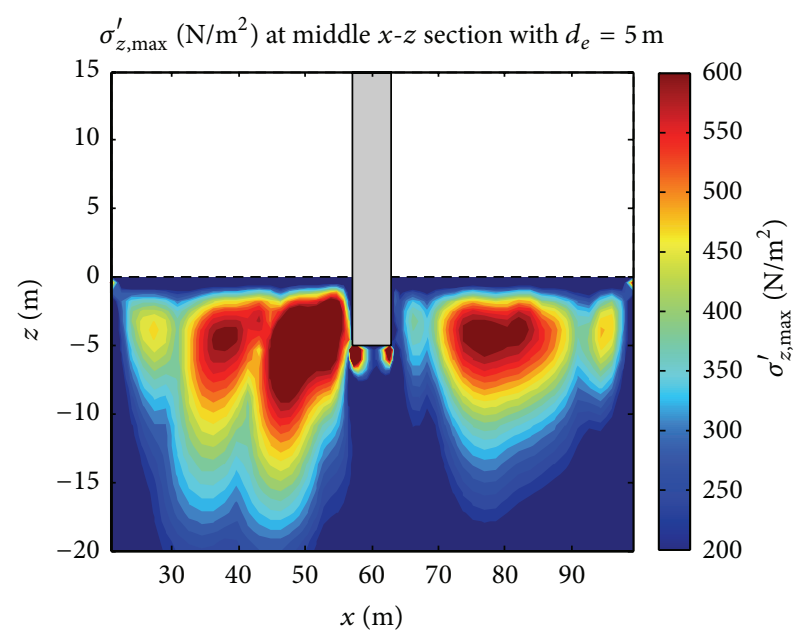

(b)

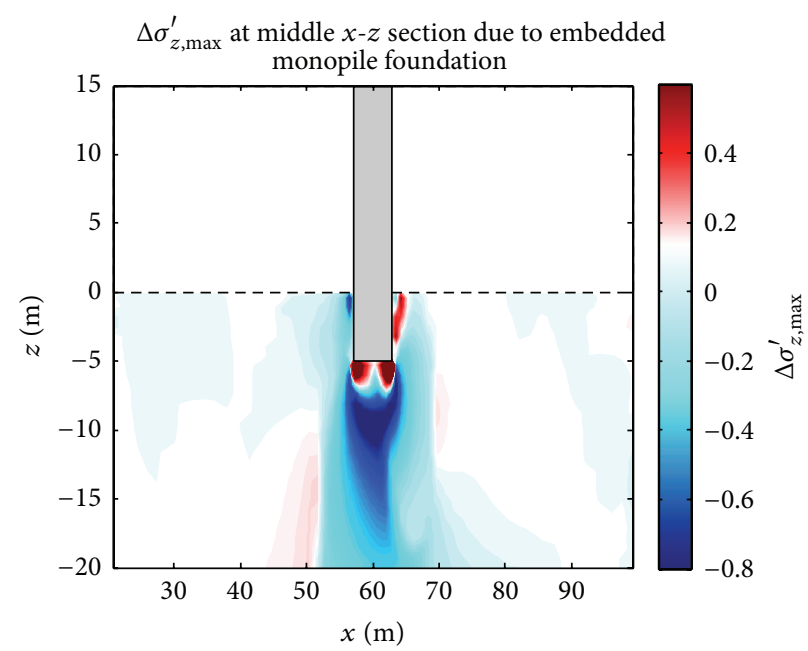

(c)

FIGURE 7: Distributions of the maximum vertical effective normal soil stress at middle $x-z$ section with the embedded depth $d_{e}=0 \mathrm{~m}$ (a), $d_{e}=5 \mathrm{~m}(\mathrm{~b})$, and its relative change (c) due to the embedded monopile foundation $\left(H=2 \mathrm{~m}, T=4 \mathrm{~s}, S_{r}=0.985\right.$, and $\left.K=5 \times 10^{-3} \mathrm{~m} / \mathrm{s}\right)$.

seabed depth until it reaches a peak value and then gradually decreases towards the seabed bottom. The embedded monopile foundation decreases $\sigma_{z \text {, } \max }^{\prime}$ at front side of foundation and in the majority of seabed below the foundation and increases $\sigma_{z, \max }^{\prime}$ at lee side of foundation and locally below the two lower corners of foundation. This is because the foundation corners act as a discontinuity or singularity point of soil skeleton, leading to a local concentration of soil stress. Figure 8 shows the results at middle $y-z$ section. The embedded monopile foundation increases $\sigma_{z, \max }^{\prime}$ at both lateral sides of foundation and locally below two lower corners of foundation and decreases $\sigma_{z, \max }^{\prime}$ in the majority of seabed below the foundation. Results indicate that the embedded monopile foundation considerably affects the local distribution of soil stress around the foundation.

4.3. Significance of the Embedded Monopile Foundation for Pore Water Pressure. Figure 9 presents the comparison of $p_{\max }$ profiles at front side (P1), lateral side (P2), and lee side
(P3) with and without the embedded monopile foundation as well as the vertical distribution of the relative difference $\left(\Delta p_{\max }\right)$. It is clearly shown that the embedded monopile foundation tends to increase and decrease the surrounding pore water pressure above and below the embedded depth, respectively. In the following analysis, the significance of these effects with respect to various embedded depths and soil parameters is discussed.

We use the maximum amplitudes of $\Delta p_{\max }$ above $(z>$ $\left.-d_{e}\right)$ and below $\left(z<-d_{e}\right)$ the embedded depth (Figure 9) to represent the significance of embedded monopile foundation, and their variation against different embedded depths, degrees of saturation, and soil permeabilities are shown in Figure 10. It is noted that different soil permeabilities should correspond to different shear modules in reality. However, the exact relationship between these two variables is yet unknown. Therefore, we keep the shear modulus constant and test different permeabilities in order to highlight the isolated effect of soil permeability. In general, it is found that (1) 


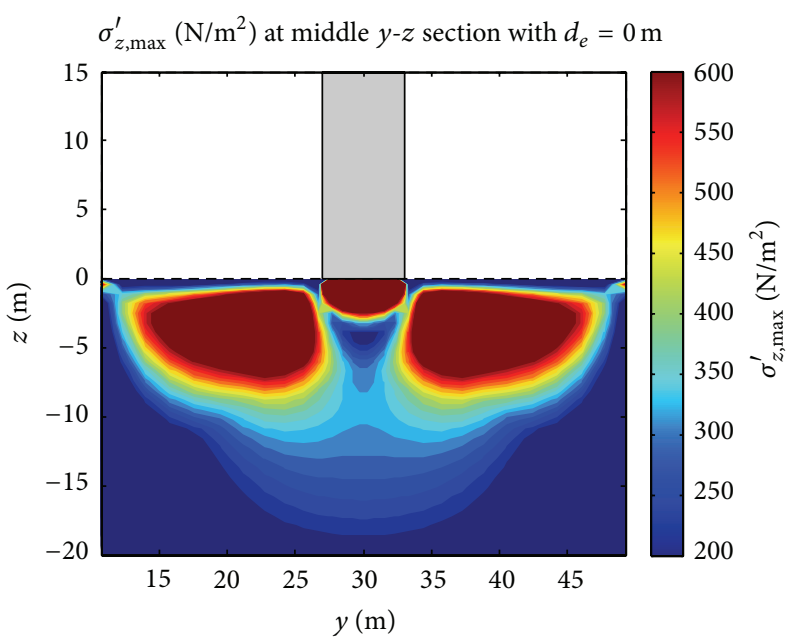

(a)

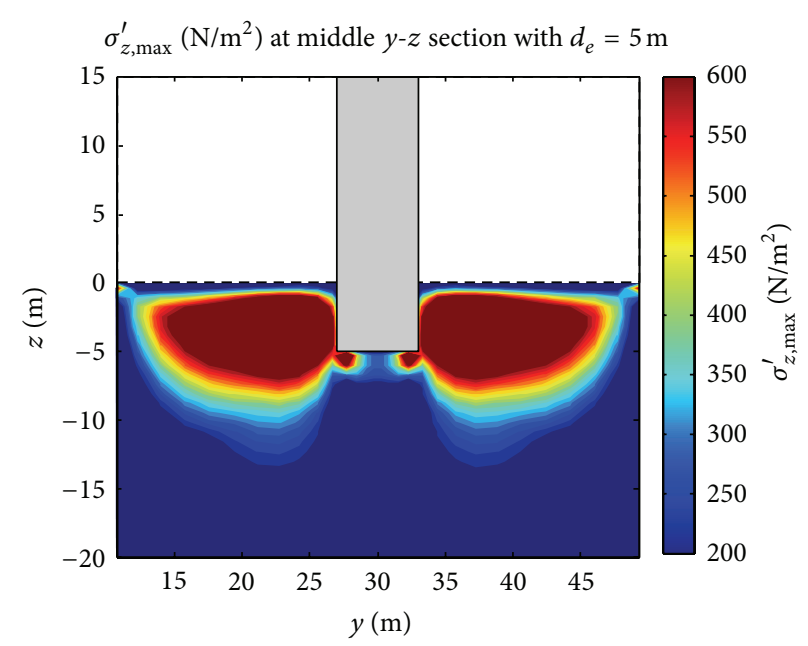

(b)

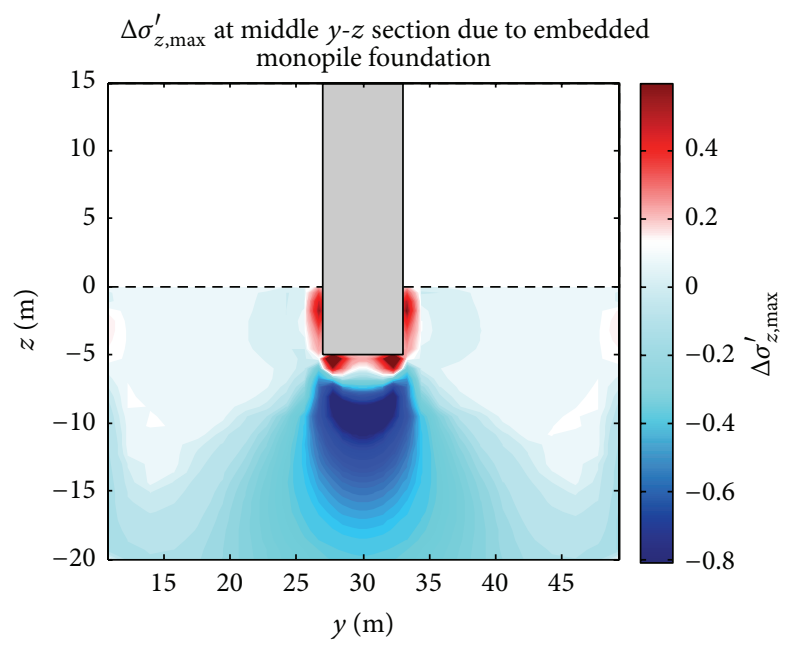

(c)

FIGURE 8: Distributions of the maximum vertical effective normal soil stress at middle $y-z$ section with the embedded depth $d_{e}=0 \mathrm{~m}(\mathrm{a})$, $d_{e}=5 \mathrm{~m}(\mathrm{~b})$, and its relative change (c) due to the embedded monopile foundation $\left(H=2 \mathrm{~m}, T=4 \mathrm{~s}, S_{r}=0.985\right.$, and $\left.K=5 \times 10^{-3} \mathrm{~m} / \mathrm{s}\right)$.

the embedded depth has negligible influence on $\Delta p_{\max },(2)$ the increasing $S_{r}$ leads to slightly decreasing amplitudes of $\Delta p_{\max }$, and (3) the increasing $K$ causes significant decreasing amplitudes of $\Delta p_{\max }$ both above and below the embedded depth. This indicates that the effects of embedded monopile foundation on pore water pressure are more significant for smaller degrees of saturation and soil permeabilities, among which the soil permeability is the dominant factor.

4.4. Significance of the Embedded Monopile Foundation for Soil Liquefaction. In this section, we further examine the effects of embedded monopile foundation on soil liquefaction, which may provide more implications for engineering practice. According to Zen and Yamazaki [28], the liquefaction criteria are expressed as

$$
p-p_{b} \geq-\left(\gamma_{s}-\gamma_{w}\right) z
$$

where the left-hand side of (6) represents the excess pore pressure which is the difference between the pore pressure inside the seabed $(p)$ and the dynamic wave pressure at the seabed surface $\left(p_{b}\right)$. The right-hand side represents the effective geostatic stress, in which $\gamma_{s}$ and $\gamma_{w}$ are the unit weights of soil and water, respectively.

Figures 11 and 12 compare the wave-induced instantaneous liquefaction zones with and without the embedded monopile foundation at middle $x-z$ section and $y-z$ section, respectively. It is interesting to found that the embedded monopile foundation tends to decrease the liquefaction depth around the structure. This is because the embedded structure increases the magnitude of pore water pressure nearby, thus decreases its vertical gradient as well as the excess pore water pressure in (6), and eventually leads to smaller liquefaction depth.

We define the relative change of the maximum liquefaction depth as $\Delta z_{\max }$, and its variation against different 

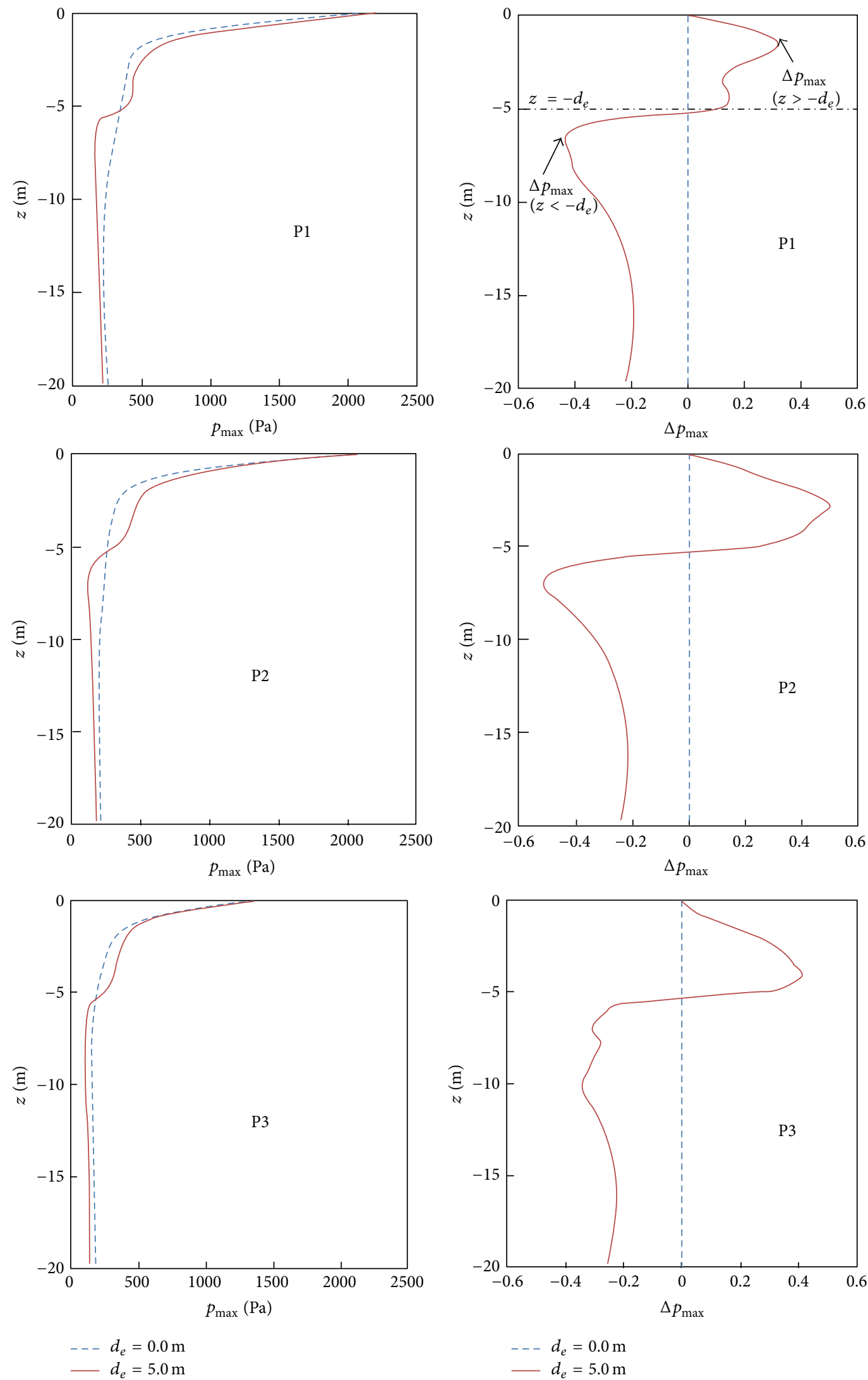

FIGURE 9: Comparison of the maximum pore water pressure profiles at front side (P1), lateral side (P2), and lee side (P3) with and without the embedded monopile foundation as well as the vertical distribution of the relative difference $\left(H=2 \mathrm{~m}, T=4 \mathrm{~s}, S_{r}=0.985\right.$, and $K=$ $\left.5 \times 10^{-4} \mathrm{~m} / \mathrm{s}\right)$. 


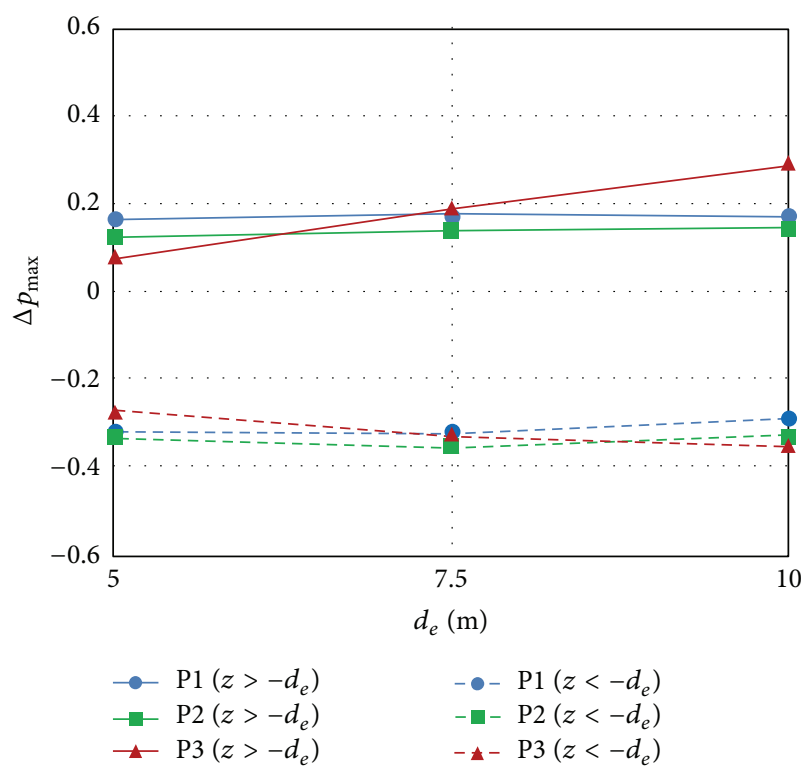

(a)

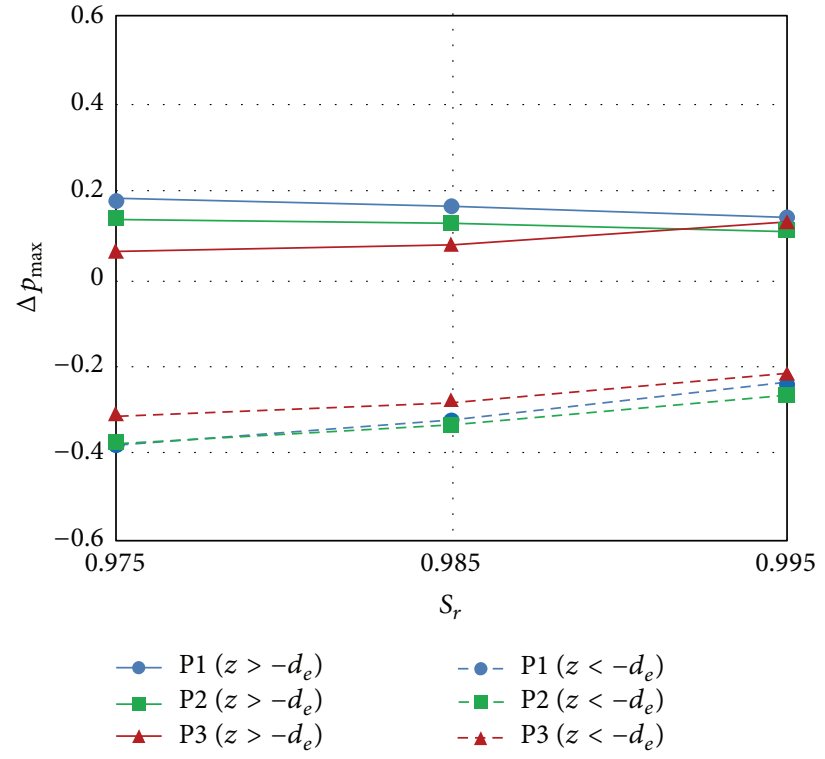

(b)

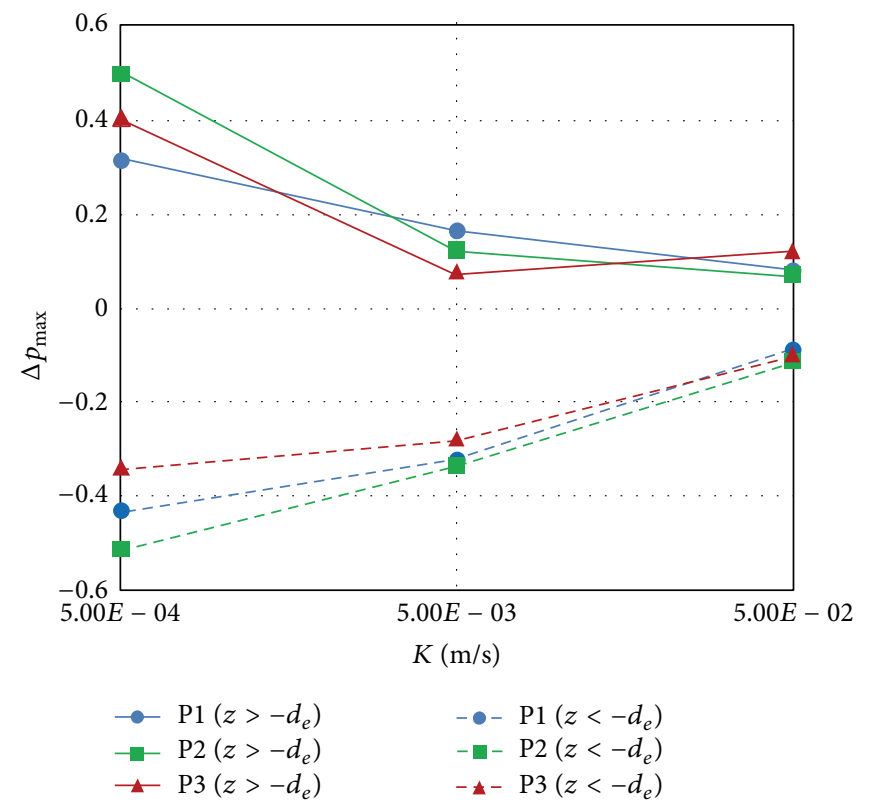

(c)

FIGURE 10: The maximum amplitudes of relative difference of pore water pressure caused by the embedded monopile foundation against (a) the embedded depth (with $H=2 \mathrm{~m}, T=4 \mathrm{~s}, S_{r}=0.985$, and $K=5 \times 10^{-3} \mathrm{~m} / \mathrm{s}$ ), (b) degree of saturation (with $H=2 \mathrm{~m}, T=4 \mathrm{~s}, d_{e}=5.0 \mathrm{~m}$, and $K=5 \times 10^{-3} \mathrm{~m} / \mathrm{s}$ ), and (c) soil permeability (with $H=2 \mathrm{~m}, T=4 \mathrm{~s}, d_{e}=5.0 \mathrm{~m}$, and $S_{r}=0.985$ ).

embedded depths, degrees of saturation, soil permeabilities, and wave heights are shown in Figure 13. It is found that (1) the embedded depth has little influence on $\Delta z_{\max }$, (2) the increasing $S_{r}$ leads to more pronounced decrease of the liquefaction depth, (3) the increasing $K$ causes greater decrease of the liquefaction depth when $K$ is not too large, but this effect vanishes when $K$ is large so that soil liquefaction no longer occurs, and (4) larger wave height results in smaller decrease of the liquefaction depth. It is indicated that the effects of embedded monopile foundation on soil liquefaction are more obvious for greater degrees of saturation, greater soil permeabilities, and smaller wave heights. This conclusion seems contrary to that in the former section regarding the effects on pore pressure. The reason is that for greater degrees of saturation and permeabilities with smaller wave heights, the soil is more difficult to be liquefied and the liquefaction depth is initially small; therefore, the embedded monopile foundation is expected to play a more significant role in a relative sense. 


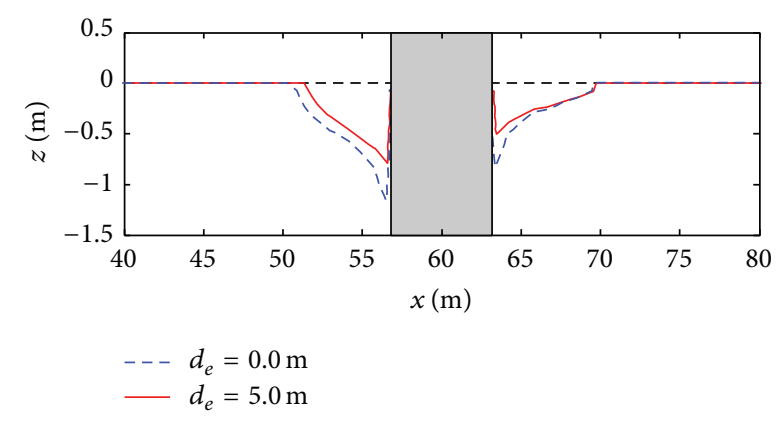

FIGURE 11: Comparison of the wave-induced instantaneous liquefaction zones at middle $x-z$ section with and without the embedded monopile foundation $\left(H=4 \mathrm{~m}, T=10 \mathrm{~s}, S_{r}=0.975\right.$, and $K=$ $\left.5 \times 10^{-4} \mathrm{~m} / \mathrm{s}\right)$.

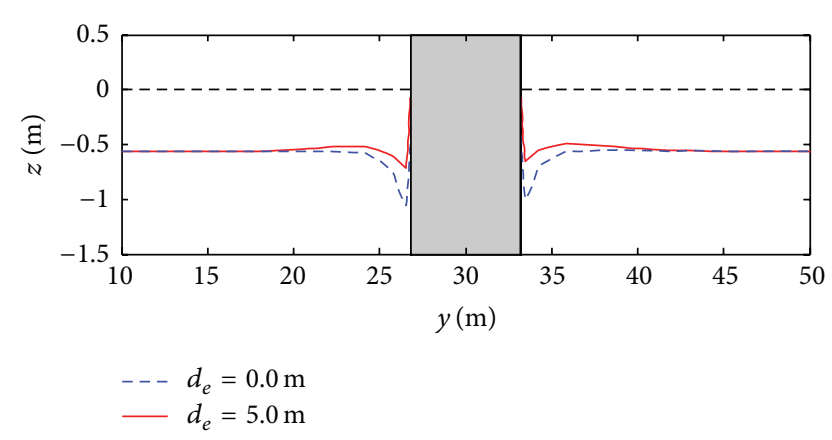

FIGURE 12: Comparison of the wave-induced instantaneous liquefaction zones at middle $y-z$ section with and without the embedded monopile foundation $\left(H=4 \mathrm{~m}, T=10 \mathrm{~s}, S_{r}=0.975\right.$, and $K=$ $\left.5 \times 10^{-4} \mathrm{~m} / \mathrm{s}\right)$.

These findings imply that neglecting the effects of embedded monopile foundation could lead to an overprediction of the soil liquefaction depth, which may serve as a useful reference for the design optimization of monopile foundation. In addition, the relationship between soil properties and the significance of embedded foundation as investigated in this study is relevant to the seabed protection methodology around structure, for example, replacement of the existing surface soil layer with suitable material [6].

This work can be further improved in future studies regarding the following issues. While the embedded foundation will change the transmission patterns of pore water pressure and tends to decrease the liquefaction depth as found in this study, the self-weight of monopile foundation can also modify the distribution of initial effective stresses through consolidation process, which is also expected to hinder soil liquefaction as extensively discussed by Ye et al. [20, 21, 29, 30]. This study preliminarily focuses on the first mechanism and adopts a classic pore pressure-based liquefaction criteria of Zen and Yamazaki [28] without considering the self-weight of structure. Nevertheless, it is considered that although the initial consolidation process could lead to some quantitative difference in the liquefaction area, it does not significantly affect the main findings of this study. Both mechanisms will be taken into account in future studies to achieve a better physical representation. Moreover, there are two types of liquefaction in marine sediments: instantaneous liquefaction and residual liquefaction. While this study focuses on the instantaneous liquefaction due to the oscillatory pore pressure, the residual liquefaction due to the build-up of pore pressure cannot be simulated in the present poroelastic model. The latter process could be important in shallow water. This requires further improvements of the numerical model.

\section{Conclusions}

A 3D integrated numerical model is developed based on a RANS wave module and a fully dynamic poroelastic seabed module. This model is used to investigate the effects of embedded monopile foundation on local porous seabed response under wave reflection and diffraction around a monopile. Based on the numerical results presented, the following main conclusions can be drawn.

(1) The embedded monopile foundation increases and decreases the maximum pore water pressure in the seabed around and below the foundation, respectively.

(2) The embedded monopile foundation decreases the maximum vertical effective normal soil stress in the seabed at front side of and below the foundation, increases the maximum vertical effective normal soil stress at lee and lateral sides of foundation, and causes a local concentration of soil stress below the two lower corners of foundation.

(3) The effects of embedded monopile foundation on pore water pressure increase as the degree of saturation and soil permeability decreases and are more sensitive to soil permeability.

(4) The embedded monopile foundation tends to decrease the soil liquefaction depth around the structure, and this effect is relatively more obvious for greater degrees of saturation, greater soil permeabilities, and smaller wave heights.

\section{Conflict of Interests}

The authors declare that there is no conflict of interests regarding the judgment and publication of this paper.

\section{Acknowledgments}

This work was supported by the National Natural Science Foundation of China (51209082, 51209083, and 41306033), the Applied Basic Research Fund of the Ministry of Transport (2014329224330), the Open Project of Key Laboratory of Engineering Sediment of Ministry of Transport at Tianjin Research Institute for Water Transport Engineering 


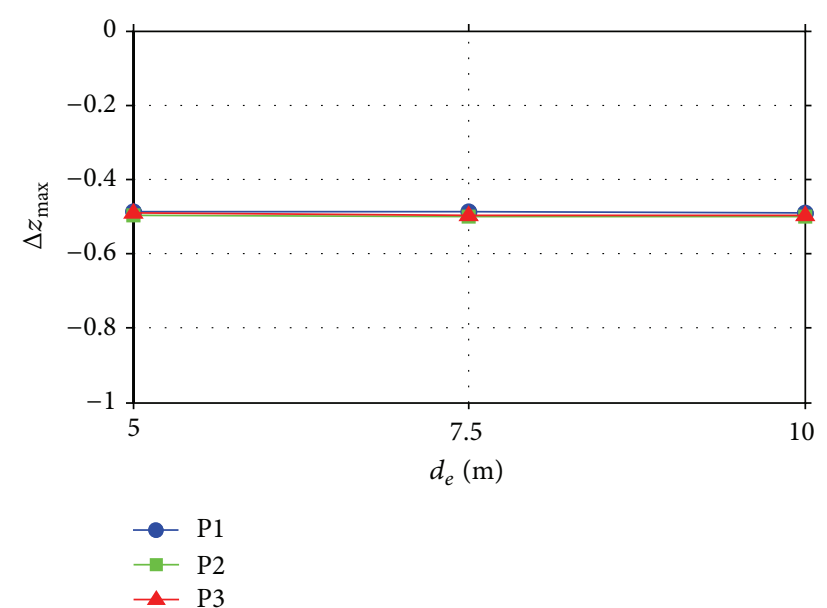

(a)

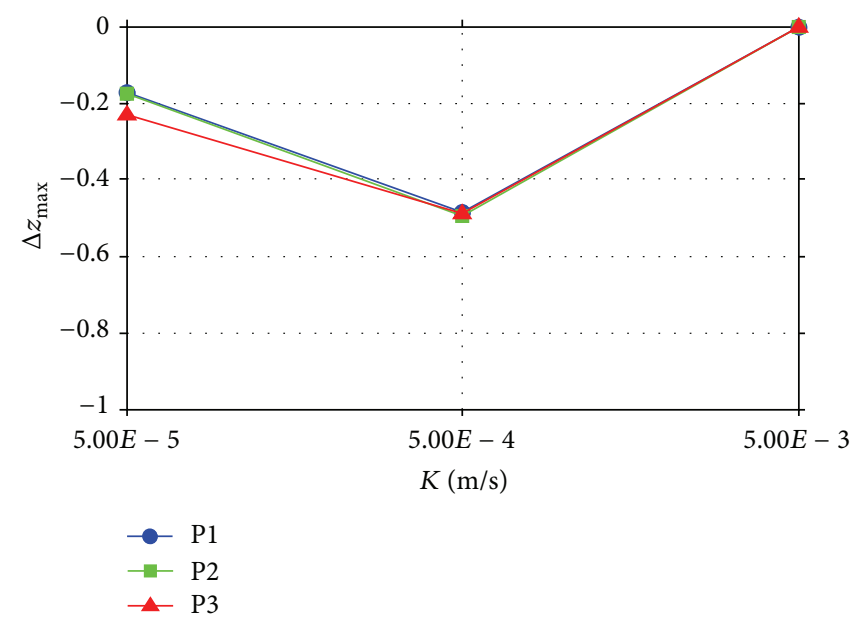

(c)

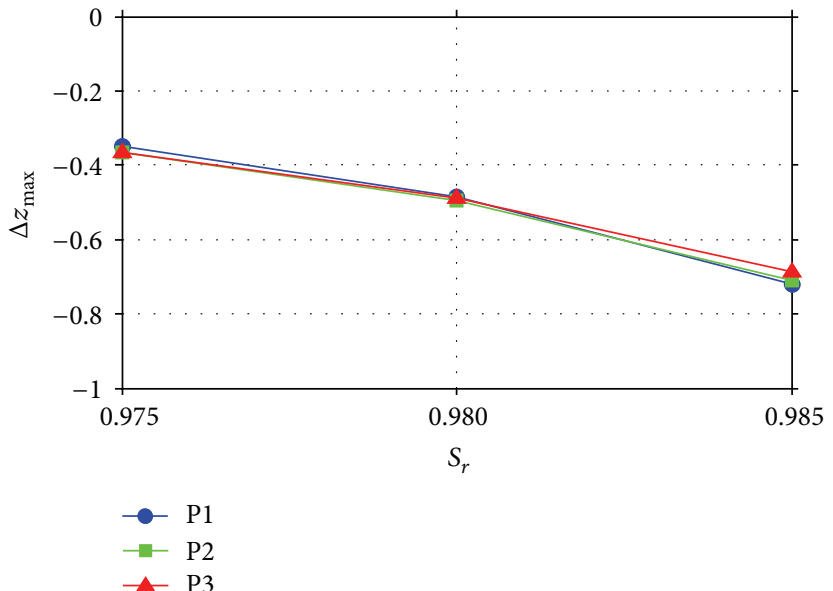

(b)

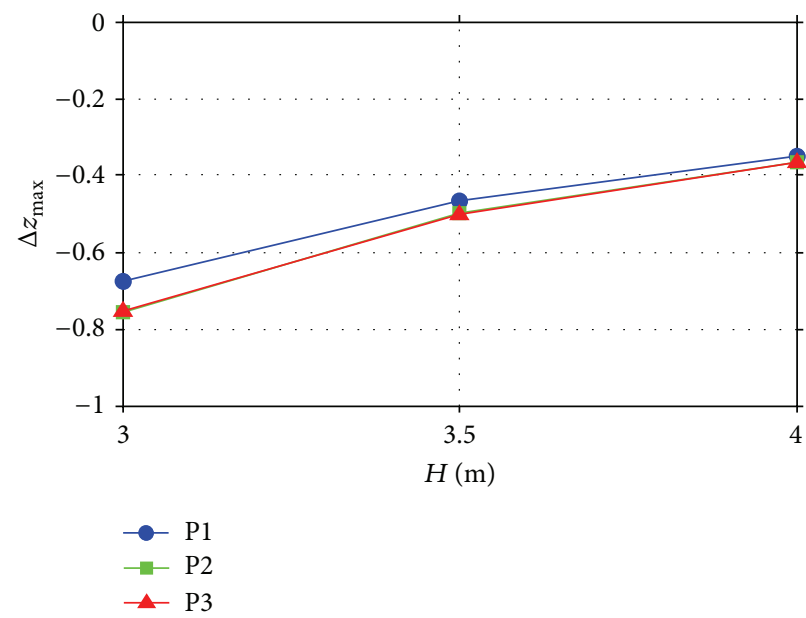

(d)

FIGURE 13: The relative difference of the maximum liquefaction depth caused by the embedded monopile foundation against (a) the embedded depth (with $H=4 \mathrm{~m}, T=10 \mathrm{~s}, S_{r}=0.980$, and $K=5 \times 10^{-4} \mathrm{~m} / \mathrm{s}$ ), (b) degree of saturation (with $H=4 \mathrm{~m}, T=10 \mathrm{~s}, d_{e}=5.0 \mathrm{~m}$, and $K=5 \times 10^{-4} \mathrm{~m} / \mathrm{s}$ ), (c) soil permeability (with $H=4 \mathrm{~m}, T=10 \mathrm{~s}, d_{e}=5.0 \mathrm{~m}$, and $S_{r}=0.980$ ), and (d) wave height (with $T=10 \mathrm{~s}, d_{e}=5.0 \mathrm{~m}$, $S_{r}=0.975$, and $\left.K=5 \times 10^{-4} \mathrm{~m} / \mathrm{s}\right)$.

(2015TKL0101), the Fundamental Research Funds for the Central Universities (2015B15514), and Jiangsu Graduate Research and Innovation Plan Grant (no. CXLX11_0450).

\section{References}

[1] S.-P. Breton and G. Moe, "Status, plans and technologies for offshore wind turbines in Europe and North America," Renewable Energy, vol. 34, no. 3, pp. 646-654, 2009.

[2] P. Doherty and K. Gavin, "Laterally loaded monopile design for offshore wind farms," Proceedings of Institution of Civil Engineers-Energy, vol. 165, no. 1, pp. 7-17, 2012.

[3] N. M. Hansen, Interaction between seabed soil and offshore wind turbine foundations [Ph.D. thesis], Technical University of Denmark, Kongens Lyngby, Denmark, 2012.

[4] X.-J. Li, F.-P. Gao, B. Yang, and J. Zang, "Wave-induced pore pressure responses and soil liquefaction around pile foundation," International Journal of Offshore and Polar Engineering, vol. 21, no. 3, pp. 233-239, 2011.
[5] H. Y. Zhao, D.-S. Jeng, Y. Zhang, J.-S. Zhang, H. J. Zhang, and C. Zhang, "3D numerical model for wave-induced seabed response around breakwater heads," Geomechanics and Engineering, vol. 5, no. 6, pp. 595-611, 2013.

[6] K.-T. Chang and D.-S. Jeng, "Numerical study for wave-induced seabed response around offshore wind turbine foundation in Donghai offshore wind farm, Shanghai, China," Ocean Engineering, vol. 85, pp. 32-43, 2014.

[7] T. T. Sui, C. Zhang, Y. K. Guo et al., “Three-dimensional numerical model for wave-induced seabed response around monopile," Ships and Offshore Structures, 2015.

[8] W. Rodi, Turbulence Models and Their Application in Hydraulics: State-of-The-Art Review, IAHR Publication, 1993.

[9] P. Lin and P. L.-F. Liu, "Internal wave-maker for Navier-Stokes equations models," Journal of Waterway, Port, Coastal and Ocean Engineering, vol. 125, no. 4, pp. 207-215, 1999.

[10] M. A. Biot, "Theory of propagation of elastic waves in a fluidsaturated porous solid. Part I. Low frequency range," Journal of the Acoustical Society of America, vol. 28, pp. 168-178, 1956. 
[11] M. A. Biot, "Theory of propagation of elastic waves in a fluidsaturated porous solid, part II: high frequency range," Journal of the Acoustical Society of America, vol. 28, pp. 178-191, 1956.

[12] D. S. Jeng, M. S. Rahman, and T. L. Lee, "Effects of inertia forces on wave-induced seabed response," International Journal of Offshore and Polar Engineering, vol. 9, no. 4, pp. 307-313, 1999.

[13] D. S. Jeng, Porous Models for Wave-Seabed Interaction, Springer, 2013.

[14] T. Yamamoto, H. L. Koning, H. Sellmeijer, and E. V. Hijum, "On the response of a poro-elastic bed to water waves," Journal of Fluid Mechanics, vol. 87, no. 1, pp. 193-206, 1978.

[15] S. Okusa, "Wave-induced stresses in unsaturated submarine sediments," Geotechnique, vol. 35, no. 4, pp. 517-532, 1985.

[16] A. Verruijt, Elastic Storage of Aquifers, Academic Press, 1969.

[17] Y. Tsui and S. C. Helfrich, "Wave-induced pore pressures in submerged sand layer," Journal of Geotechnical Engineering, vol. 109, no. 4, pp. 603-618, 1983.

[18] M. B. C. Ulker, M. S. Rahman, and M. N. Guddati, "Breaking wave-induced response and instability of seabed around caisson breakwater," International Journal for Numerical and Analytical Methods in Geomechanics, vol. 36, no. 3, pp. 362-390, 2012.

[19] D.-S. Jeng, J.-H. Ye, J.-S. Zhang, and P. L.-F. Liu, "An integrated model for the wave-induced seabed response around marine structures: model verifications and applications," Coastal Engineering, vol. 72, pp. 1-19, 2013.

[20] J. H. Ye, D. S. Jeng, P. L.-F. Liu, A. H. C. Chen, R. Wang, and C. Q. $\mathrm{Zhu}$, "Breaking wave-induced response of composite breakwater and liquefaction in seabed foundation," Coastal Engineering, vol. 85, pp. 72-86, 2014.

[21] J. H. Ye, D. S. Jeng, and A. H. C. Chan, "Consolidation and dynamics of 3D unsaturated porous seabed under rigid caisson breakwater loaded by hydrostatic pressure and wave," Science China Technological Sciences, vol. 55, no. 8, pp. 2362-2376, 2012.

[22] J. H. Ferziger and M. Peric, Computational Methods for Fluid Dynamics, Springer, Berlin, Germany, 2002.

[23] T. J. Barth, "Aspects of unstructured grids and finite-volume solvers for the Euler and Navier-Stokes equations," AGARD Report 787, Special Course on Unstructured Grid Methods for Advection Dominated Flows, AGARD, Neuilly-sur-Seine, France, 1992.

[24] P. L.-F. Liu, P. Lin, K.-A. Chang, and T. Sakakiyama, "Numerical modeling of wave interaction with porous structures," Journal of Waterway, Port, Coastal and Ocean Engineering, vol. 125, no. 6, pp. 322-330, 1999.

[25] C. V. Deutsch and A. G. Journel, GSLIB: Geostatistical Software Library and User's Guide, Oxford University Press, 1997.

[26] J. R. C. Hsu and D. S. Jeng, "Wave-induced soil response in an unsaturated anisotropic seabed of finite thickness," International Journal for Numerical and Analytical Methods in Geomechanics, vol. 18, no. 11, pp. 785-807, 1994.

[27] Y. H. Maeno and T. Hasegawa, "Evaluation of wave-induced pore pressure in sand layer by wave steepness," Coastal Engineering Journal, vol. 28, pp. 31-44, 1985.

[28] K. Zen and H. Yamazaki, "Oscillatory pore pressure and liquefaction in seabed induced by ocean waves," Soils and Foundations, vol. 30, no. 4, pp. 147-161, 1990.

[29] J. H. Ye, D. S. Jeng, R. Wang, and C. Q. Zhu, "A 3-D semi-coupled model for fluid-strutures-seabed-interaction (FSSI-CAS 3D): model and verification," Soils and Foundations, vol. 40, pp. 148$162,2013$.
[30] J. H. Ye, D. S. Jeng, R. Wang, and C. Q. Zhu, "Numerical simulation of the wave-induced dynamic response of poroelastoplastic seabed foundations and a composite breakwater," Applied Mathematical Modelling, vol.39, no. 1, pp.322-347, 2015. 


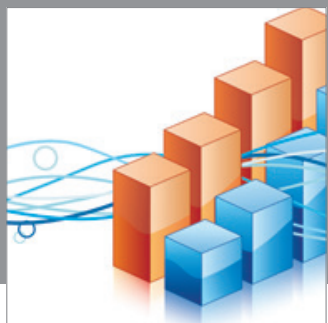

Advances in

Operations Research

mansans

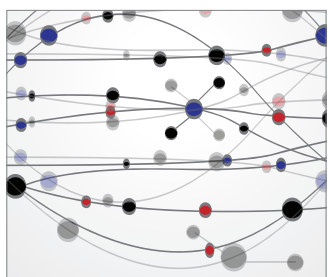

The Scientific World Journal
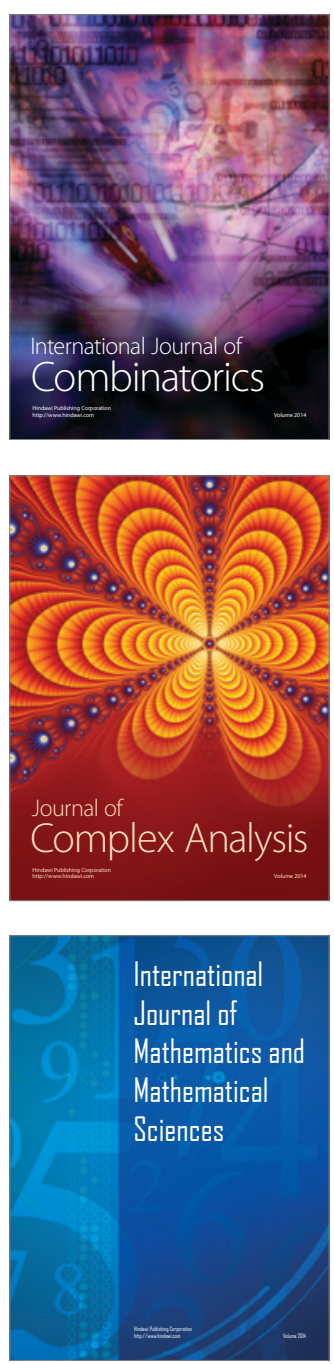
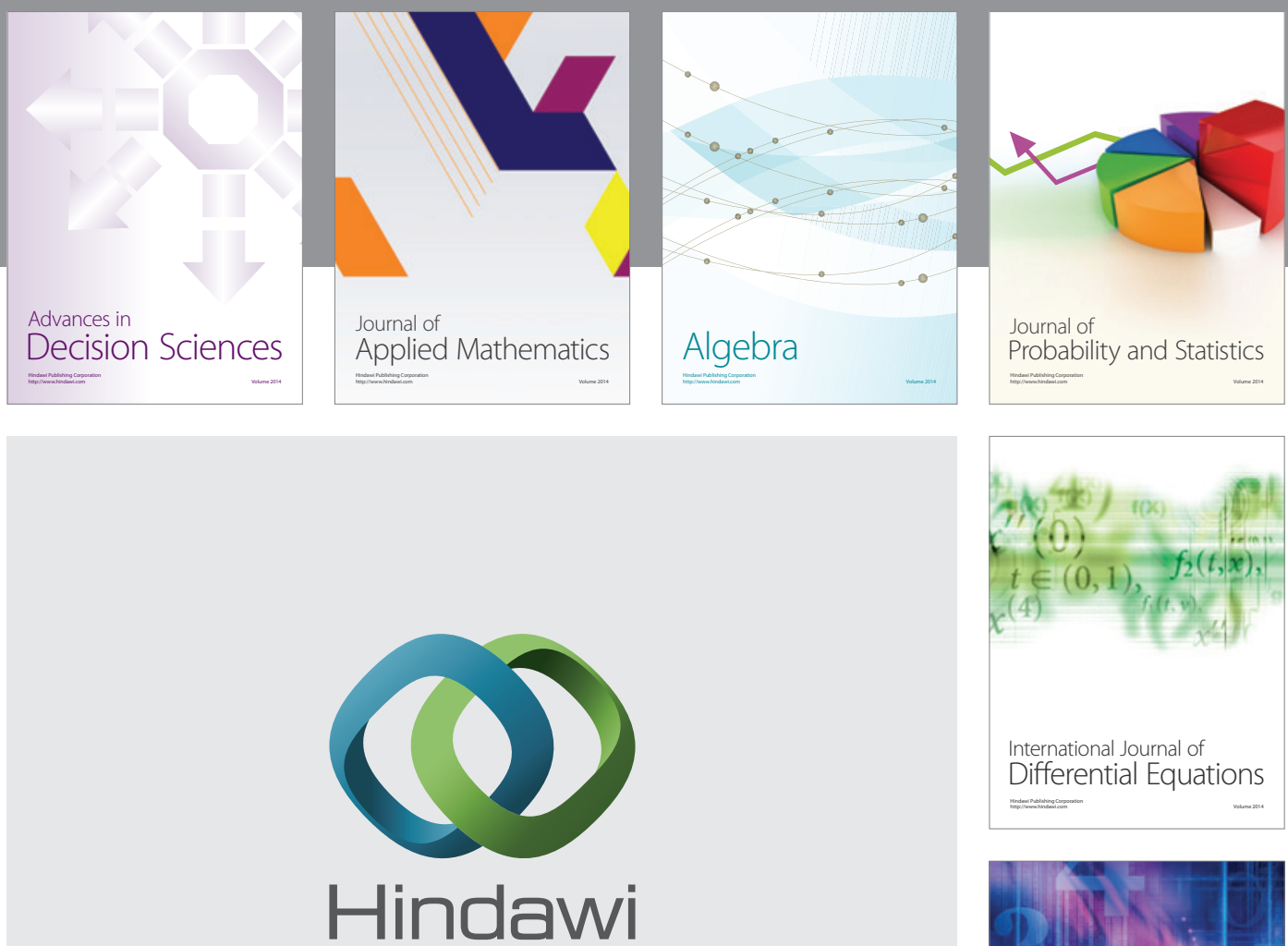

Submit your manuscripts at http://www.hindawi.com
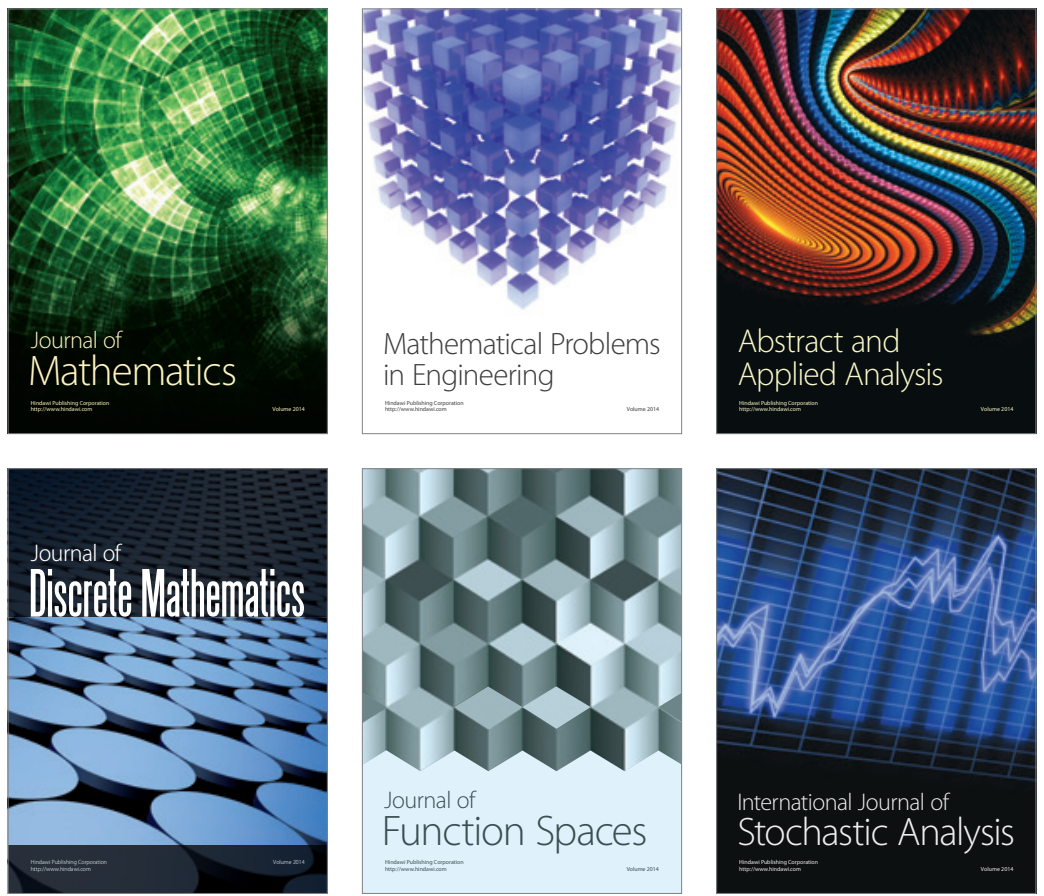

Journal of

Function Spaces

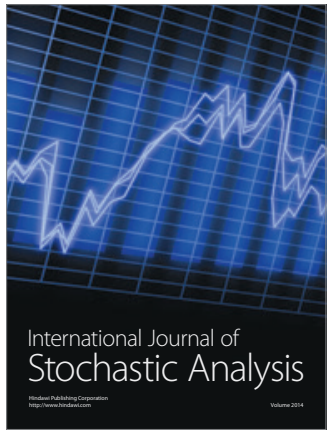

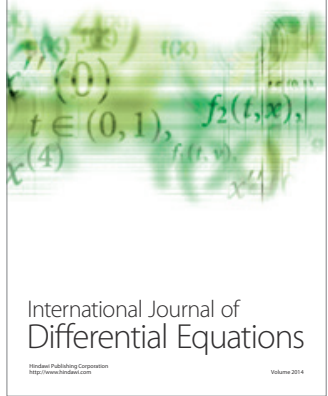
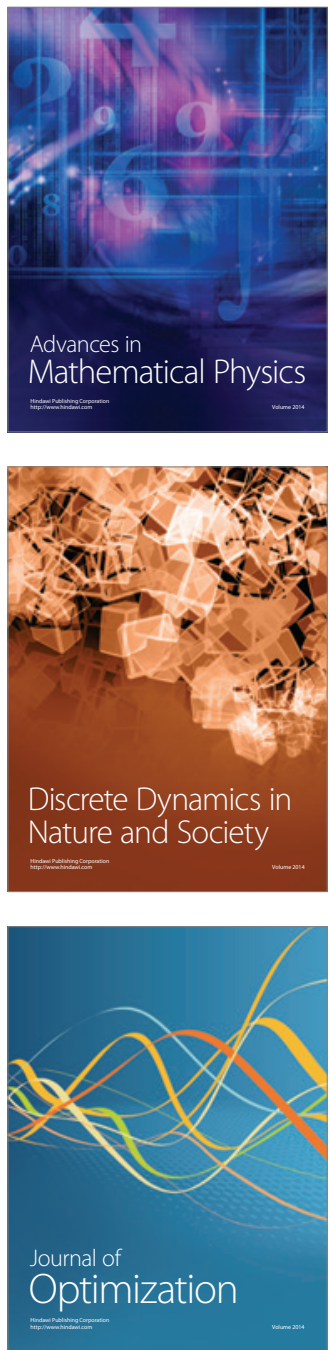